\title{
Networks of Informal Caring: A Mixed-Methods Approach*
}

\author{
Alasdair Rutherford and Alison Bowes \\ School of Applied Social Science, University of Stirling, Scotland

\section{RÈSUMÈ}

La prise en charge des soins des personnes âgées est un phénomène complexe et un sujet de préoccupation politique urgent. En rassemblant des littératures sur les prises en charge des soins venant des domaines de la gerontologie sociale et de l'economie, nous rapportons les résultats d'un projet de méthodes mixtes explorant les réseaux de prise en charge des soins informels. A l'aide de données quantitatives provenant du « British Household Panel Survey » (sondage officiel sur des menages britanniques) ainsi que des entretiens qualitatifs avec des personnes âgées et des travailleurs sociaux informels, nous décrivons des réseaux de prise en charge des soins informels différents, et les facteurs et processus décisifs qui ont contribué à la formation des réseaux. Une approche basee sur des réseaux de prise en charge des soins permet une étude à la fois quantitative et qualitative, et peut être utilisée pour explorer plusieurs questions importantes.
ABSTRACT
Care for older people is a complex phenomenon, and it is an area of pressing policy concern. Bringing together literature on care from social gerontology and economics, we report the findings of a mixed-methods project exploring networks of informal caring. Using quantitative data from the British Household Panel Survey together with qualitative interviews with older people and informal carers, we describe differences in formal care networks, and the factors and decision-making processes that have contributed to the formation of the networks. A network approach to care permits both quantitative and qualitative study, and the approach can be used to explore many important questions. 
* This work was supported by the Economic and Social Research Council (ESRC) through the Centre for Population Change.

Manuscript received: / manuscrit reçu :

Manuscript accepted: / manuscrit accepté :

Mots clés: vieillissment,

Keywords: aging, care network, informal care, mixed methods

La correspondance et les demandes de tirés-à-part doiventêtreadressées à: / Correspondence and requests for offprints should be sent to:

Alasdair Rutherford, Ph.D.

School of Applied Social Science

University of Stirling

Stirling, FK9 4LA, United Kingdom

(ar34@stir.ac.uk)

Informal or unpaid care is a critical element of the care system in the United Kingdom: recent estimates suggest that these carers deliver care to the value of $£ 119$ billion per year, and that 12 per cent of adults are involved in caring (Carers UK, 2012). Carers are more likely to be women than men, and carers are typically in the 50-59 age group. Most carers (40\%) are caring for parents or parents-in-law, while more than a quarter (26\%) care for their spouse or partner (Carers UK). The significance of informal care is argued to be increasing: demand for unpaid care in the United Kingdom is expected to reach three million recipients in 2050 (Karlsson, Mayhew, Plumb, \& Rickayzen, 2006), while demand for care is projected to outstrip supply after 2017 (Pickard, 2014).

Furthermore, the universe of unpaid care is changing: these changes relate to the "supply" of unpaid care, particularly affected, it is argued, by changes in the female labour force (Pickard, Wittenberg, Comas-Herrera, King, \& Malley, 2007; Spiess \& Schneider, 2003) but also by changes in the welfare mix, involving an increasing emphasis on care at home, coupled with public expenditure cuts. Our research, covering the United Kingdom, has identified shifts from personal care tasks to other tasks in response to the free personal care policy in Scotland (Bell \& Bowes, 2006), changing attitudes to care among the baby boomer 
generation (Bell, Bowes, \& Heitmueller, 2007), and potentially significant impacts from rising levels of education, new patterns of migration of both carers and care recipients, and increased housing wealth (Bell et al.). Others have explored the potential impact of changing family structures and dynamics on the availability of unpaid care (Appelbaum, Bailey, Berg, \& Kalleberg, 2002; Lilly, Laporte, \& Coyte, 2007; Lyon \& Glucksmann, 2008; Williams, 2004; Williams, 2010).

Informal care has received research attention from a variety of disciplinary perspectives. Methods used have tended to be polarised, with researchers either drawing on rather generalised questions in large-scale surveys (Hirst, 2001), or conducting smaller-scale qualitative work. Rummery and Fine (2012) critiqued existing approaches to care arguing that the economics of care are not well understood, and Francis and McDaid (2009) further identified methodological issues in attempts to do so. These include differences in identifying whose care is included and how time spent is measured or evaluated. They acknowledged various researchers' attempts to understand care as a labour process and to identify the financial costs of care both at the individual and societal levels, but argued that this work can provide only a partial analysis as long as underlying conceptual issues remain. Rummery and Fine suggested that these conceptual problems come at least in part from the failure of different perspectives to learn from one another and thereby enable a more nuanced understanding of the complexities and dynamics of care to be developed.

In the context of increasing demand and changing resources for care, this article describes our study and in doing so brings together perspectives from economics and social gerontology on the basis of a mixed-methods approach to understand some contemporary dynamics of informal care. The study aimed to identify care network patterns and to examine how these operate in practice. Our central focus was informal care, while including more formal sources of care within our conceptualisation of networks. We also sought to identify dynamics of care 
networks over time with particular reference to decisions made by individuals and households.

\section{Background}

We refer to two broad literatures on unpaid care, divided by disciplinary boundaries. The economics literature focuses on the strategic decisions of carers and care recipients, and on how these interact with economic activities such as employment. The social gerontological literature describes care as a network of support, dependent on relationships with family, friends, and neighbours and developing through time. There is little crossover between these two literatures.

Much of the economic analysis of provision of unpaid or informal care by family members derives from Becker's (1981) economic theory of the family. His original focus was on a "unitary" or "common preference" view of care provision, where family members share a common set of preferences. Contributions by others such as Hiedemann and Stern (1999) and Engers and Stern (2002) have developed the analysis of the care decision using a gametheoretic framework. For example, Pezzin, Pollak, and Schone (2007) have focused on alternative residential arrangements once a need for care has been determined. These include residential care, paid-for home care, and unpaid care provided by one or more children.

Economists have demonstrated that parent-child location decisions can be important in determining informal care. Konrad, Kunemund, Lommerud, and Robledo (2002) argued that children may act strategically to change the costs of providing care to their parents as they grow older. Children may be concerned about whether their parents are receiving adequate care, but would prefer not to provide that care themselves. Rainer and Siedler (2009) confirmed that siblings are more mobile than only children. In common with Konrad et al. (2002), they highlighted the role of sibling rivalry as a determinant of caregiving. Bell and 
Rutherford (2013) showed the importance of both individual and geographic factors in care network formation. There are many motivations for providing informal care, from altruism towards family through to expectations of future financial rewards. Informal care affects intergenerational bequests and inter-vivos transfers (Bernheim, Shleifer, \& Summers, 1985; Norton \& Van Houtven, 2006). Informal care relationships can be one-to-one, many-to-one, one-to-many, and may be reciprocal. Pickard (2012) showed evidence of substitution between nursing home or hospital care and very intense co-resident intergenerational care for older people. However, provision of informal care is not without cost as carers' health typically suffers (Clyburn, Stones, \& Hadjistavropoulos, 2000; Haley, 2003; Pinquart \& Sorensen, 2003; Schulz et al., 2003).

In contrast with the one-to-one or many-to-one models of caring favoured in the economics literature, there is a social gerontological literature that describes care relationships as a network both within and outside families. The conceptualisation of networks in this literature in part derives from Kahn and Antonucci's (1980) notion of a "convoy", a network of supporters that surrounds an individual across their lifespan, consisting of supporters more closely linked and others more distant, represented as a series of concentric circles (p. 273). The convoy changes over the lifespan, as supporters become more or less important. This concept has been developed and tested (Antonucci \& Akiyama, 1987) and researchers have come to focus on a wider concept of social relations (Antonucci et al., 2013). While our concept of the care network can be linked to this work, our central focus on care distinguishes our work from this broader analysis of social networks.

More generally, social gerontological literature highlights a number of points regarding care networks. Women have larger social networks than men, and among older people, close relatives dominate the networks (Phillipson, 2001). Daughters are significant sources of support, particularly for mothers (Bris, 1993; Phillipson). Network sizes are stable as people 
age, but become increasingly made up of family rather than friends (van Tilburg, 1998).

Those who are older, unmarried, childless, or in poor health are least likely to have adequate support networks in place (Keating, Oftinowski, Wenger, Fast, \& Derksen, 2003). The factors that lead families to provide informal care include gender, status, proximity, marital status, other caring demands, and mutual affection (Finch \& Mason, 1993; Lewis \& Meredith, 1988; Ungerson, 1987). Wenger (1991), using qualitative and then quantitative (surveys in 1979 and 1987) research methods, developed a typology of informal support networks which aimed to be useful for predicting possible demands on health and social care services, calling our attention to questions about the resilience or vulnerability of different networks, and making an important link with formal services.

This literature has tended to focus on the networks that provide informal care, and has not generally included formal care provision as part of the network, thus making it difficult to ascertain how informal care intersects with other forms of support. Stoller and Pugliesi's (1991) longitudinal study indicates that informal care networks may reach a tipping point, where increasing need of the person being supported grows beyond the capacity of the network: their work, among that of others, suggests that the focus on informal care alone is unhelpful. A further limitation of the literature concerns the preoccupation with network size and composition. Wenger and Keating (2008) noted that little is known about how networks evolve and change across the aging lifespan, although Carpentier and Ducharme (2005) proposed a method of studying these processes by combining network and narrative analysis. Furthermore, while there is research that describes how people perceive their caring (Roe, Whattam, Young, \& Dimond, 2001), we have little understanding of how they move into caring roles, and come to self-identify as carers. Lewis and Meredith's (1988) classic study demonstrates that daughters slip imperceptibly into the role. Willyard, Miller, Shoemaker, and Addison (2008) found that there was little negotiation of caregiving tasks within families, and other work has suggested that the role "creeps up" on relatives as a person's needs increase 
(Nolan, Grant, \& Keady, 1996). Gans and Silverstein's (2006) work examines expectations of caring roles and varying norms of filial obligation, but does not illuminate actual caring behaviours.

\section{Methods}

Our study used a pragmatic mixed-methods approach (Creswell \&Plano Clark, 2011), combining quantitative analysis of data from the British Household Panel Survey (BHPS) with qualitative fieldwork conducted in rural Scotland in order to improve understanding of the complexities of informal care. Ethical approval for the research was granted by the School of Applied Social Science Ethics Committee of the University of Stirling.

An informal care network is a map of the caring relationships between individuals both within and outside the household. Constructing data on informal care networks involves transforming survey data on the provision and receipt of informal care into a dataset where the caring relationship, rather than the individuals, is the unit of observation.

We used data from the British Household Panel Survey to construct a dataset of care networks. The BHPS is an annual longitudinal household survey, started in 1991, of around 8,000 adults aged 16 and older in the United Kingdom. Each year in the BHPS, individuals within each household are directly observed, and are asked about any informal caring they provide both within and outside the household. Carers can be matched to care recipients within households in order to map their informal care relationships. Household members are also asked detailed questions about the formal health and social care services that they have accessed in the previous year. From this, hospital and general practitioner (GP) visits, home help, social work support, and other formal services can be plotted in the network. Lastly, household members are asked about informal support that they receive from children, or give to others, who reside outside the household. Details are given about the type of support and the frequency of contact with children. 
In this study, we used data from one wave of the BHPS for adults aged 50 and older surveyed in 2006. This year was selected as additional questions were asked about support received from outside of the household that allowed more detail to be added to the care networks than would be possible in other waves of the survey. These additional questions provided richer care network data, but the additions meant that it was not possible to fully exploit the longitudinal design of the BHPS. The quantitative survey data were transformed so that each row represented a caring relationship between two individuals. The direction of the caring link was from "carer" to "care recipient" in each record, and reciprocal care was recorded as two links in the network, one in either direction. In addition to informal care relationships, formal care links were created for accessing home help, meals, social work support, physiotherapy, and hospital visits. The networks constructed in this way were then grouped by type in order to provide descriptive statistics in the analysis that follows. This quantitative description of caring networks provided a sense of the scale and complexity of care. It also allowed us to identify how common the care networks described in the qualitative analysis are in the population.

Figure 1 provides an example of a care network. The shaded circles represent individuals, whereas the light circles represent formal health and social care services. The arrows illustrate caring relationships. The large rings represent the level of data observed on each agent. Within the inner ring, agents are inside the observed household, and data are held on their detailed characteristics. The second ring contains agents referred to in the data but not directly observed. These include formal care services such as visits to hospital or to the doctor, as well as informal help from children outside the household. Beyond their existence, relatively little is known about the characteristics of these agents. The third ring represents caring relationships at the edge of the care network which are unobserved. That is, we were not able to directly observe whether external children providing informal care also provide informal care to others, or themselves access formal health or social care services. 
Qualitative data were gathered to allow the construction of more-detailed networks of support at the household level than is possible through the analysis of survey data. The interview data also enabled us to study factors that led to the formation and development of caring networks, and the decision-making processes of both carers and care recipients. The qualitative data presented in this article were gathered during fieldwork conducted in one local authority area in rural Scotland during the summer of 2011. We used purposive sampling to recruit older people receiving informal care, and individuals providing informal care to older people, through a range of local authority, charitable, and voluntary groups as well as by publicity in the local newspaper.

Semi-structured interviews lasting one to two hours were conducted with 25 households. The interviews covered a housing history, map of family locations, questionnaires on health, and formal and informal care. With the interviews, we explored the intersections of care and housing decision making, and planning for the future. Interviewees included both older people (22) and informal carers (11), and we conducted interviews whenever possible that were matched within households (6 carer/care-recipient-matched households achieved). For purposes of this article, we selected 17 households grouped into four network types. We did not include eight of the households interviewed: four due to saturation in the representation of spousal care cases, three due to incomplete interviews, and one whose sensitive situation could have been revealing. The interview transcripts were manually coded by topic using QSR International's NVivo 10 software, and the codes were then combined and examined to produce a thematic analysis. We also used the data to construct networks of formal and informal care using the same approach as with the quantitative data. Finally, the care histories of each case were mapped to permit exploration of decision-making processes and their consequences. 
Comparing the care networks generated from the secondary quantitative data and the primary qualitative data helped us to explore the limitations of the aspects of informal care which the survey data captured. The depth of the qualitative interviewing, and the opportunity to identify informal caring not necessarily classed as such by the carer, permitted a more indepth exploration of care complexity than would be possible with one method alone. For this article, we classified each household by its caring network structure, and these were then cross-referenced with the emerging themes to explore the points of comparison.

\section{Findings}

Analysis of networks recorded in both the quantitative and qualitative data led to the classification of care networks into four broad types, as Table 1 shows. The classifications were derived as a combination of living and care arrangements. Type 1 networks were households where spousal care is the primary source of care. This may have been reciprocal between spouses, and there may also have been support from children or others outside the household. Type 2 networks had no informal carers living within the household, and all informal care was provided from external individuals, usually children or grandchildren. This network type has been sub-divided into those living alone and those living with others. Type 3 networks include individuals or couples living with children who provide care. Type 4 networks include all other living arrangements, such as primary informal care from extended family or non-family members. Table 1 also reports the classification of care networks from both the quantitative and qualitative analysis. The quantitative data are reported both as a number of households and as a survey-weighted estimate of the proportion of older households. The qualitative data report the number of households in each category and their fieldwork label.

The survey data show that the most common network type was individual older people living alone with some form of support from their children living outside the household. This 
support is broadly defined and could include anything from occasional help with chores through to regular intimate personal care. These households had no informal care provided from within the household. Older people receiving care from a spouse made up a smaller percentage of households, but a significant number of people, and often a caring spouse, was also receiving some form of care themselves. Older people living with their children were much rarer. The last category contains a selection of alternative networks, including living with a sibling, living with a non-family member, and living alone with informal support from wider family and friends.

No households in the fieldwork were classified as network type $2 b$, where an older person lived with another (such as a spouse) and received informal care only from children outside of the household. However, many more households were interviewed where individuals received support from spouses within as well as children outside of the households than might have been expected from the quantitative analysis of network types. We suggest two explanations for this. First, the quantitative data may be under-reporting informal care from spouses. Many of the informal support activities carried out by spouses were described qualitatively as being part of what was expected in a relationship, and as a duty rather than a choice. This representation of the activities might not have led individuals to identify themselves as an informal carer, although the more in-depth qualitative interviews did record these activities. This is an issue for the quantitative analysis, but one where the qualitative interviews shed more light. This issue suggests that some of the $2 \mathrm{~b}$ networks were actually early-stage type 1 networks, a distinction which the quantitative data did not capture.

Second, the qualitative fieldwork may have missed households where the only support was from children outside the household. If the individuals in the household did not classify the types of informal support that they received from children as informal care, then they may not have responded to the requests to participate in the fieldwork. The quantitative data instead 
asked all older people questions about the different types of help that adult children might provide to parents, without labelling that help as care. In this sense, the quantitative data captured a dimension of help that the qualitative fieldwork focussing on care missed out on. This finding lends support to the mixed-methods approach that was selected for this research project. Each method provides a window to a different aspect of the complexities of care networks.

Table 2 provides some descriptive statistics for households by network type, drawn from the survey data. With the exception of multi-person households with informal care from outside, households with care networks were significantly older than those without. The oldest households were those where the older person was living with their children. The average ages here are suggestive of a progression, from external support from children, to internal support from spouses, to internal support from children. Those living alone were the most likely to be in socially rented accommodation, although these were not the households with the lowest incomes. There was not a significant urban/rural variation in the types of care networks. The largest household sizes were those where the older person was living with a child.

Table 3 shows the age and sex profile of the participants in the qualitative fieldwork. Male participants tended to be older and to be care recipients, while younger female participants were more likely to be included in the sample as care givers.

We now explore each network type in turn, describing the characteristics of the networks from the quantitative analysis and discussing the main themes emerging from the qualitative analysis. In the account that follows, pseudonyms are used to indicate household (letter) and marital status (Mr., Mrs., Miss).

\section{Network Type 1: Care from Spouse within Household}


Table 4 shows the breakdown of spousal care networks by the number of formal and informal care links in the network. More than two-thirds of spousal care networks have two or more sources of informal care. Most networks also include some links to formal care services. There is, however, a relatively large percentage (34\%) of small care networks in the top left of the table with only one or two informal care links and one or no formal care links.

Six households interviewed involved spouses living together, where one described themselves as caring for the other at the time of the interview. These households were located in a range of environments including small towns (3), a village (1), and a more rural area in an isolated property (2). One couple (Mr. and Mrs. G) had moved back to the area from abroad due to health problems; Mr. and Mrs. I had moved to a more accessible property; Mr. and Mrs. P had retired to the area from England within the past three years. The other three couples were longstanding residents of their homes and had lived and worked locally for many years. Two couples (H and Q) were trying to sell their houses to move to a more accessible property but had not so far succeeded. There were thus clear influences from care issues on the location and properties that people were living in, but also illustrations that for some, these were not ideal. The Ps had been able to make preparations for the future:

We've actually just, these last few weeks, had raised beds put in the garden so that we don't have to bend. They are really raised so if [Mr. P]'s ever in a wheelchair he will actually not be restricted by doing some gardening. So we've been thinking about it for a long time. (Mrs. P)

The Qs had recently attempted to address their housing difficulties:

We put our name down for the sheltered housing but just recently ... I went in and asked because of the situation [Mrs. Q having mobility problems]. (Mr. Q)

In five of these households, the wife was the primary caregiver for her husband. It is also notable that in only one household (Mr. and Mrs. Q) was significant support provided by 
children, despite the fact that five of the households did have living children. Perhaps unsurprisingly, it was this one household where the husband was the primary carer that had significant involvement of the couple's children.

In most cases, the care role had developed gradually over time as the health of one partner had deteriorated, although Mrs. Q's stroke had resulted in a more immediate need for care. The histories of households and care arrangements collected revealed a range of pathways that emphasise the varying genesis and trajectories of care arrangements: these are not apparent from the quantitative data.

The analysis shows that the health of carers is important: carers Mrs. G, Mrs. I, Mrs. P, and Mr. Q all had recent health problems of their own which impacted on their ability to provide informal care to their spouses. Mrs. I, for example, had become ill, and the social links she had within the area were crucial to her own and her husband's capacity to deal with this and continue his care. Mrs. P, whose mother was also in a nearby care home, had started to develop some memory problems which she described as making things more difficult in supporting her husband who had Parkinson's disease: she herself recognised that her caring challenges could only increase in the future. Deterioration in the carer's health would have serious implications for their partners who depended on them for care, and they were aware of this.

These cases bring home forcefully the potential for care relationships to be compromised suddenly and seriously by illness, for example, with such illness being more likely the greater the age of the carer. Spousal care partnerships thus emerge as being potentially vulnerable to sudden stressors. Further quantitative analysis could explore how these care partnerships respond over time to challenges to the carer: they may, for example, result in home moves or admissions to hospital or residential care of either the carer or the cared-for partner. 
Social networks were an important form of support, although this appeared to be the case primarily for carers rather than care recipients. Networks such as social clubs, former colleagues, support groups, and sporting activities provided an "escape" for carers. Mrs. G, for example, belonged to a number of community groups, and she enjoyed her involvement with these - though Mr. G would have preferred her to stay at home. She explained:

I don't think [Mr. G] could manage here on his own ... he doesn't go outside and he is isolated, and he has isolated himself and he tries to isolate me. (Mrs. G)

Where couples had support from wider social networks, this seemed to be channelled and maintained primarily by the carers, as the people receiving care often had health or mobility issues which made leaving the house problematic. There is a risk here that could magnify the negative impact of the carer's falling ill, as it would not only leave a care gap but also in many cases sever the connection to wider social networks.

In four out of the six households, there was significant tension around the giving and receiving of informal care. Mr. C, for example, was concerned that his wife was, as he put it, being "brainwashed" by carers' support meetings into believing that their situation would significantly deteriorate as Mr. C's health declined, and that she would soon be unable to cope. He described these "horror stories", which seemed to make them both reluctant to discuss what the future might hold, and explained how they tended to speak about things when prompted by professionals, rather than between themselves:

Needing care ... nobody ever takes that into consideration ... until it happens to them. Once it happens to them, then they start thinking about it ... Well, we haven't discussed [formal care] as such. The thing is, we don't discuss it between ourselves as much as when the manager from the day centre comes along and speaks to us. (Mr. C)

Mr. and Mrs. G had some disagreements over her care for her mother, and the wider family's responsibilities for care. Mrs. H was glad to be healthy enough to look after her 
husband, but did at times feel resentful for the impact that her caring responsibilities were having on her life despite her own good health. Mr. H was reluctant to raise this with his wife. Mr. Q found his wife's confusion quite stressful, particularly when she worried about him whenever he was out of sight. A common theme here is the difficulty in discussing these issues between spouses: this can be linked with the comments about preferring not to think ahead about care needs, illustrating the challenge that developing needs for care can present, and calling into question any rational actor model of care decision making.

For most of the households with children, there was a reluctance to ask for help. This was sometimes based on practical grounds, such as distance or the existing caring responsibilities of sons and daughters for their own children. Daughters were more likely to be seen as potential informal carers than sons. However, there was also a strong sense that children "have their own lives" and should not be expected to get involved in providing care. In some cases, this is on the grounds of gender: for example, as Mr. P explained:

We've got a son who actually lives around [nearby], but I wouldn't ask him to help out because basically he's got his own life to live. I was born in a tradition where the daughters looked after the old timers [...] I didn't do that for my parents and I wouldn't ask my son. (Mr.P)

None of the householders planned to move in with their children if their needs increased. Aye, we never ever discussed staying with anybody on a permanent basis, no. I wouldn't consider that. Given the option, I wouldn't consider it as an option. (Mr. Q)

Even if [my daughter] suggested it, [...] I would say, "you're not really suggesting that, you are just saying it out of the goodness of your heart." (Mr. H)

For most of the households, very little planning for care was undertaken prior to developing a need. When a need for care developed, planning appeared to be driven by the spouse providing informal care. Decisions were taken primarily through couples discussing 
the situation with social workers or care managers, and in some cases involved discussions with children.

\section{Network Type 2: Care from Child(ren) Outside the Household}

Living with care from children as the primary source of informal care was the most frequent care network type. However, it is worth noting that this support could range from occasional light support to intensive personal care. Table 5 shows the proportion of household networks by the number of formal and informal care links for households where an older person lived alone, while Table 6 shows the network sizes for households of two or more individuals (primarily spouses). Nearly two-thirds of the households received only informal support in both cases. Nearly 85 per cent of those living alone had only one informal care link, while more than half living in larger households had two or more informal care links.

Five households were interviewed in which informal support came primarily from children outside the household. All the households were people who lived alone, and all were longstanding residents of the area, four having spent their whole lives there and one, over 30 years. These households were thus noticeably less mobile than the households with spouse carers. All had children living nearby from whom they received a range of help and support, sometimes complemented by support from formal services. For example, Mr. B received his son's help with shopping and gardening, and used formal services in the form of a day centre, home help, and lunches delivered four days a week by a Meals on Wheels service. This range of provision was typical of this group: it is worth noting that the proximity and availability of support from children did not mean that these households did not access formal services.

The variety of arrangements, even among this small group, was striking, and illustrates the variations that exist beneath the statistical data. Mrs. L received regular personal care from formal services: her daughter's role was to organise and be "in charge" of these services. Mrs. $\mathrm{S}$ attended a day centre; her granddaughter helped with cleaning, and her grandson, with 
shopping and gardening. Mrs. W also received support from her grandchildren who lived locally. Mr. T received daily visits from his daughter, who helped with household tasks: he could drive, and he did some of his own shopping. His daughter focused on what she perceived as his isolation, and his reliance on her for his main support, and was concerned at the impact this was having on her responsibilities in her own household.

These arrangements illustrate a range of relationships and caring tasks that are not well captured in the surveys. They demonstrate variability underlying the types of networks that can be identified from the survey data and suggest a need for improved survey data that might capture the variability and allow its implications to be explored. For example, the implications of cross-generational care extending to grandchildren have not been widely discussed, nor has the role of a family "care manager" been much considered, though it is akin to Corcoran's (2011) "advocacy" model. Both of these could have implications for future care policy and particularly for our understanding of the total social costs of care.

For those older people who were living alone, there was a strong theme of independence. Mrs. S, for example, stated:

I make my own decisions. I never discuss any with them ... They come to me. (Mrs. S)

Mrs. W appreciated her family, but did not want to rely on them:

I've got a very good family - not that I want them to look after me. (Mrs. W)

And Mr. T's daughter observed:

He'd rather be dead than have to depend on someone. (Ms. T)

It is noticeable that there was more male involvement in caregiving where the older person lived alone, with both sons and grandsons playing a significant role. However, there was still a gendering of caring roles, with male help more likely to involve gardening, shopping, and home improvements, and women more likely to deliver more domestic and personal support - 
although it should be noted that the "care manager" identified in our interviews was female. In several respects, therefore, the care that women provided accorded with the literature that emphasises the parallels between caring and traditional women's roles. However, these interviews highlight that what carers do is clearly not confined to such roles, nor did these participants see caring as defined in that way. Furthermore, tasks such as the care manager task are revealed in these qualitative data: for Mrs L, this role was clearly of great importance in supporting the care arrangements.

These interviews also show the importance of adult grandchildren in providing informal support. Both Mrs. S and Mrs. W received regular visits and support from their grandchildren, and this was at least as important to them as support from their children. Informal support of this type is not captured in quantitative datasets such as the BHPS.

None of the interviewees expressed a desire to move in with their children in the future. All interviewees said that increased formal care, or ultimately residential care, would be their choice if their needs increased. Mrs. W briefly lived with her daughter in England ("down south"), but found that this did not work out, mainly because she found being away from friends and familiar places difficult. For most of the interviewees, it was the thought of being a burden on their children that informed their views. For Mrs. S, as noted, it was maintaining her independence, and particularly her role in the family, which led her to rule out living with her children, although she currently was receiving significant support from both her children and grandchildren. She also mentioned the experience of caring for her own mother as influencing her decision to prefer residential care if her own needs increased. She did not want to place similar demands on her own children.

Well, I kept my mother for over 12 years, and I said "there is no way I'm coming to any of you" [her children] because my mother tended to be a very demanding person .... (Mrs. S) 
The impact of people's previous experiences on their decisions about their own care may be particularly important in the light of the literature that suggests people have little information on which to base decisions. We are likely to find path-dependent decisionmaking: this could be seen as rational, but based on restricted and particular knowledge arising from experience. In the absence of a spouse, our data suggest that children may be more involved in decision-making about care. This is a further factor introducing complexity in care trajectories, whereby the knowledge and experience of a new generation comes into play.

Family members were very important in the social networks of this group of respondents. An extreme example is Mr. T, whose networks focused almost entirely on his family, leading his daughter, as we have noted, to worry about his isolation and dependence on the family. He did attend adult day care, but it was not clear that this provided strong social support. Other respondents had a range of social contacts, to which they attached considerable importance: Mr. B, for example, spoke about his "good neighbours" of many years and the network of connections he had through day care, in addition to the contacts he kept with family both local and overseas. Although they lived alone, these individuals seemed more socially connected and embedded in their local communities and scattered families than did those receiving care from spouses.

\section{Network Type 3: Care from Children Living within Household}

Only a small proportion of care networks include parents living with their children.Table 7 shows the breakdown of care networks by the number of formal and informal care links. More than one-third of the networks involving parents living with their children have no formal care links.About one-fifth of the networks are made up of three to five informal care links, and more than one-quarter of these larger care networks have no formal care. 
Three households were interviewed in which those receiving care were living with their children. All three interviewees were female, and two had moved in with children when, in old age, they were no longer able to cope living on their own. These two (Mrs. O and Mrs. X) had moved in to their daughters' homes because they needed more care and support than their daughters could provide at a distance: the decision to move appears to have been driven by necessity and to have been seen as an alternative to moving into residential care. Mrs. $\mathrm{O}$ in particular was described as needing someone to be in the house all day and night, and she experienced confusion regularly. It seems likely that Mrs. O and Mrs. X, when younger, valued their independence as did others in the sample, given the mention of their desire to stay out of residential care. In contrast to the other two interviewees, Mrs. E had moved in with her daughter prior to needing care, upon returning from living abroad.

The decision-making process for each of the households was different. Mrs. E moved in with her daughter before needing care. Mrs. O moved in as the result of a crisis, precipitating an increased need for support. Both Mr. and Mrs. X moved in with their daughter together after a period of discussion when Mr. X's health was declining. All three acknowledged the challenges of moving to live in someone else's house. For Mrs. O and Mrs. X, who moved later in life, establishing new social networks proved difficult, leading to feelings of isolation.

It is certainly notable that all three households were relatively wealthy, with the children having houses of sufficient size to accommodate their relatives comfortably. It is also significant that in all three cases it was the parents who moved to live with their children, and that the mothers (and one father for a time) lived with their daughters, and that both daughters and son-in-laws were in paid work. The daughters were the primary informal carers, with sons mentioned much less frequently in descriptions of caring activities.

The networks in which these people were involved varied. Those whose move had been precipitated by care needs had more restricted networks. Mrs. O attended a day centre, but did 
not have a wider social circle beyond the family. Mrs. X was acquainted with neighbours, but most of her contact was with the family. Mrs. E was a member of a "very supportive" church congregation, and described her social life as linked with the church and with the day centre she attended. Mrs. E had had time to build her own network before developing care needs, and this may explain her lesser dependency on her family for social contact.

Mrs. X reflected on some of the difficulties she had found settling in to her daughter's home:

It's been extremely difficult to settle in the sense of no longer being in your own home, no longer your own place. So it's been a long time to make it feel like it's home, as opposed to just a place to live. (Mrs. X)

This feeling of dependency is reflected in all three of these cases.

\section{Network Type 4: Other Care Networks}

The "other" network types observed in the survey data include older people caring for older children, care from siblings, care from non-family, and care provided to others outside the household. Three "other" households were interviewed where caring arrangements included living with siblings, living with extended family, and living with non-family. The category as a whole, as the quantitative data illustrate in Table 8, is quite diverse, although much smaller than the other categories. The three cases here indicate the extent of the variation that may exist. We focus on each one separately for illustration: the cases overall suggest the importance of understanding how less-common household arrangements may generate alternative care arrangements or, indeed, care arrangements that parallel those of the more common types.

Miss FA and Miss FB were sisters in their late 70s who lived together in an affluent coastal town. They were born locally, neither was married, and they had always lived together. They 
had no children but did have nephews living fairly locally. The sisters received local authority home care to help with shopping and housework, and some informal support from a nephew with managing money. The sisters also supported each other, and attended day care once a week. They moved into their current flat following the encouragement of their nephews who felt that they were not coping with the stairs in their old house. They expressed some minor resentment concerning this, feeling that they were pushed into moving and that their current flat was a bit small. Explaining that they had lived in their old house for many years, they explained:

We were sad to leave it. The family just about herded us out .... We were'nae [were not] keen - we would have stuck for a few more years. (Misses FA and FB)

They did not really know their neighbours, and although they got out and about a little in the summer they did not have much social contact beyond attending the day care. They felt that there was now some pressure to consider moving into more formal or residential care, but were determined to stay together in their own home:

The only thing wrong with us is that the legs are going a bit, but otherwise we're healthy and strong and we don't feel the need for any more help than we're getting now, you see. (Misses FA and FB)

Like the type 1 households involving spouses, this case showed two people whose lives were relatively self-contained within their household and who did not have extensive networks: in this case too, the potential impact of loss of one person could be considerable.

Mrs. J, aged 83, lived in a small coastal village with her nephew, his wife, and their son. When her husband passed away, she sold her house and bought a large house together with her nephew. Mrs. J had poor mobility, and some health problems, which did affect her daily and social activities: she felt that her needs were increasing. She received some informal care from her nephew and his wife, but felt that they were both out quite a lot. Relationships 
within the household were not described very positively, and the arrangement was not working out as hoped. This was causing Mrs. $\mathrm{J}$ to feel depressed and anxious, but she felt strongly that she did not want to live alone. She had few social contacts, although she did attend day care once a week. This case is particularly illustrative of unintended and unforeseen consequences of what had seemed appropriate choices at one time.

Mrs. Y, aged 70, lived in a coastal village with her friend Mr. Z, aged 83.Mrs. Y had previously lived in London before moving up to Scotland about 30 years ago. Mr. Z was a friend from London who had moved up on his retirement to live with her. She provided informal care for him, but they were not involved romantically. Mrs. Y also cared for her mother, who was living nearby; and also provided support to her son who had addiction problems, and to her grandchildren. Mrs. Y described herself as being in excellent health and as very active. Mr. Z's health was fair, although he needed support, and her mother had serious mobility problems and was unable to do many things for herself. Mrs. Y described having a good social network and being very active with both friends and community groups. Mr. Z by contrast was very isolated with no family and few social contacts; this was in part by choice and in part due to his poor mobility. Mrs. Y seemed to thrive on her caring commitments: she was clearly a driving force in maintaining her supportive role, and managing a complex set of obligations. A significant group of people depended on her for support, and as such, she was the linchpin of a network, which could have collapsed were she to withdraw for any reason.

[My mother has a cleaner] Just once a week. But she makes her own bed, and I change [Mr. Z's] bed and that, don't I? And, well, I do everything really. I do everything. Make sure he gets his shower, which isn't as often as I would like. (Mrs. Y)

\section{Discussion and Conclusions}


Our study has illuminated several issues highlighted in earlier research. There is no doubt that caring is complex. We have argued that it is best understood as a network of support, which may be a complement to or substitute for formal care provision. Our conceptualisation of care networks has advanced previous research, particularly by including formal care, and exploring complementarities and substitutions in a set of real examples. Caring networks are common and increasingly important in aging societies.

We noted that caring activity has been addressed differently by several disciplines. These literatures are not well integrated, and each neglects some important aspects of care. We suggest that studying care as a network allows both the individual and social characteristics of caring relationships to be studied, bringing together literatures in economics and social gerontology. Both quantitative and qualitative methodologies, through a mixed-methods approach, are required to fully understand the phenomenon of informal care and its intersections with formal care. The quantitative analysis has allowed us to describe the pattern of care networks links, and to provide a picture of the relative frequencies of network types in the United Kingdom, grounded in large-scale survey data and moving beyond classification of types of network according to their vulnerability (e.g., Wenger, 1991), initially generated from qualitative research. Our analysis has also highlighted the diversity of network types and allowed for the exploration of the characteristics of both carers and people receiving care. The qualitative analysis allows us to focus on the factors affecting decision making, and highlighted the importance of timing and path dependency that led to the formation of care networks as we observed them. This helps understanding of how care networks change over time, a key concern of ours and of other studies, notably that of Stoller and Pugliesi (1991) but which is a little-understood area (Wenger \& Keating, 2008).

Using a mixed-methods approach, we have shown that in most cases the care networks had a strong core, with one primary informal carer. This is most likely to be a spouse or a child, 
and they may be inside or outside of the household. There is then typically a secondary layer of informal support. This is likely to be a mix of children, other family, friends, neighbours, or others in the wider community. Where older people have moved in later life, particularly those moving in with children, this secondary support network may be missing. However, several households in our fieldwork who moved to new areas either at retirement or in the early years of older age had successfully built up these support networks. The concept of the "convoy" (Antonucci et al., 2013) is helpful in representing this constitution and dynamic of care networks.

Although distance between family members is important in patterns of informal care, it is not the whole story. More-affluent children may move farther away, but they are also more likely to have the resources to provide support. However, this needs to be balanced with the choice that many older people face if moving to be nearer to children means sacrificing social networks built up over time. If this is done too late in the older person's life, then it is difficult to rebuild those networks in a new place, and this makes the move harder. Isolation can be a significant problem even for those who have lived in one place all their lives; particularly when complicated by physical mobility problems. These observations call attention to the importance of context for the development of care networks, and support Wenger's (1991) focus on the nature of engagement with family and community, as well as the importance of geographical influences (Bell \& Rutherford, 2013).

Our findings question approaches in the economics literature which adopt rational-choice models, such as Becker (1981) and the game-theoretic framework used by Heidemann and Stern (1999) and by Engers and Stern (2002). Very few of the care networks in our study were clearly planned by the individuals involved, whether in terms of financial planning, or location decisions and choices of residential care versus home care. The formation of care networks may depend on the decisions of others, often at different points in time. They also 
depend on the resources available to both potential carers and people receiving care. In several cases this can lead to crisis points, or to households being "trapped". Planning is more evident once an older person needs support, and this seems to be driven by primary informal carers, whether spouses or children. A minority of households in our fieldwork had made plans for older age, particularly in selecting their locations, choosing appropriate housing, and investigating care options. While those households who had planned seemed to be better off in terms of well-being, it is clear that they were also the households that were financially better off to start with. Access to resources is a key factor in the ability to make plans for care in older age and is an area surprisingly neglected in previous literature.

There was a seeming contradiction, as most older people with lower levels of need did not plan to accept more informal support as their needs increased, while most older people who had higher support needs did in fact receive high levels of informal support. There seemed to be great reluctance to ask for informal help, but great appreciation when it was received. Those receiving no help from children did not expect it; those who did, appreciated it but did not want to be a bigger burden, while those living with children were grateful but still saw themselves going into formal care in the future. It seems likely that these views develop and change as people get older, as they begin to confront the realities of planning care for older age. The difficulty of planning, and the reluctance to discuss these difficult issues both within families and with formal care providers, are worrying issues in the context of population aging. Thus not only are cultural expectations and values important (Corcoran, 2011), but these are also dynamic. Along with changing care needs, caring roles change, emphasising that caring is not a clearly defined role, and that its qualitative exploration is needed to unpick the wide range of possibilities: despite our small sample of real cases, we were able to demonstrate a range of roles and their development. Such research moves beyond work which defines caring more particularly, such as much of that based on the large-scale surveys and their acceptance of a simple self-identification of respondents as "giving care". 
Our mixed-methods approach has also highlighted some shortcomings in each approach to studying care. The quantitative survey data focus on care activities rather than on outcomes, and so does not capture the quality of care. It also does not capture indirect caring roles, such as where children help to coordinate formal care, and wider, less frequent informal care within communities. Our qualitative fieldwork helped to shed light on each of these issues. While the fieldwork allowed us to explore the complexity of care networks, the survey data show that there is significant variation even within care network types that is difficult to adequately capture in a smaller qualitative sample. The differences in the frequencies of care network types between the survey data and our fieldwork snowball sample also suggest that some types of care networks are more difficult to recruit into this sort of study, such as multiperson households receiving care from outside of the household where none of the occupants identify themselves as an informal carer. The use of mixed methods thus raises new issues for research on caring.

This study did have some limitations. The sample for the qualitative element of the work was relatively small, and could not therefore represent the full range of possibilities for variability of care networks. However, we have focused our analysis on the core types of network, highlighting throughout the fact that reality is complex and nuanced. The large-scale survey data analysed, while large, require work to generate data on care networks, and are limited in terms of the detail of caring responsibilities that the data cover, hence the need for further qualitative work. The survey data are also essentially carer-defined, as the data starting point is people who define themselves as carers. The qualitative data were collected in a rural area; however, the quantitative analysis indicated no effects of rurality. We are not able to say from the data whether or how rural location may have affected the care networks. Finally, it is important to note that the study relates to one cultural context, and we recognise that norms regarding caregiving vary cross-culturally (Corcoran, 2011). However, this fact does not 
negate the utility of the concept of care network, but it does necessitate attention to context to make sense of care processes and choices in practice.

In conclusion, a network approach to care permits both quantitative and qualitative study, and can be used to explore a number of important research issues. Above all, a multidisciplinary approach is necessary to understanding caring relationships in older age, and that significant benefit is to be gained from drawing on disparate care literatures and using multiple data sources.

\section{References}

Antonucci, T. C., \& Akiyama, H. (1987). Social networks in adult life and a preliminary examination of the convoy model. Journal of Gerontology, 42(5), 519-527.

Antonucci, T. C., Ajrouch, K. J., \& Birditt, K. S. (2013). The convoy model: Explaining social relations from a multidisciplinary perspective. The Gerontologist,

Appelbaum, E., Bailey, T., Berg, P., \& Kalleberg, A. L. (2002). Shared work/valued care: New norms for organizing market work and unpaid care work. Washington, DC: Economic Policy Institute.

Becker, G. S. (1981). Altruism in the family and selfishness in the market place. Economica, 48(189), 1-15.

Bell, D., \& Bowes, A. M. (2006). Financial care models in Scotland and the UK. London, UK: Joseph Rowntree Foundation.

Bell, D., Bowes, A., \& Heitmueller, A. (2007). Did the introduction of free personal care in Scotland result in a reduction of informal care? WDA-HSG Discussion Paper, No. 2007-3. St. Gallen, Switzerland: World Demographic Association. 
Bell, D., \& Rutherford, A. (2013). Individual and geographic factors in the formation of care networks in the UK. Population, Space and Place, 19(6), 727-737.

Bernheim, B. D., Shleifer, A., \& Summers, L. H. (1985). The strategic bequest motive. Journal of Political Economy, 93(6), 1045-1076.

Bris, H. J. (1993). Family care of dependent older people in the European community. Luxembourg: Stationary Office Books.

Carers UK. (2012). Facts about carers 2012. Policy Briefing. London, UK: Carers UK.

Carpentier, N., \& Ducharme, F. (2005). Support network transformations in the first stages of the caregiver's career. Qualitative Health Research, 15(3), 289-311.

Clyburn, L. D., Stones, M. J., \& Hadjistavropoulos, T. (2000). Predicting caregiver burden and depression in Alzheimer's disease. The Journals of Gerontology Series B: Psychological Sciences and Social Sciences, 55(1), S2-S13.

Corcoran, M. A. (2011). Caregiving styles: A cognitive and behavioral typology associated with dementia family caregiving. The Gerontologist, 51(4), 463-472.

Creswell, J. W., \& Plano Clark, V. L. (2011). Designing and conducting mixed methods research. Thousand Oaks, CA: Sage.

Engers, M., \& Stern, S. (2002). Long-term care and family bargaining. International Economic Review, 43(1), 73-114.

Finch, J. D., \& Mason, J. (1993). Negotiating family responsibilities. London, UK: Tavistock/Routledge.

Francis, J., \& McDaid, D. (2009). SCIE's work on economics and the importance of informal care. In L. Cutis (Ed.), Unit costs of health and social care (pp. 27-33). Canterbury, UK: University of Kent. 
Gans, D., \& Silverstein, M. (2006). Norms of filial responsibility for aging parents across time and generations. Journal of Marriage and Family, 68(4), 961-976.

Haley, W. E. (2003). Family caregivers of elderly patients with cancer: Understanding and minimizing the burden of care. The Journal of Supportive Oncology, 1(4 Suppl. 2), 25-29.

Hiedemann, B., \& Stern, S. (1999). Strategic play among family members when making longterm care decisions. Journal of Economic Behavior \& Organization, 40(1), 29-57.

Hirst, M. (2001). Trends in informal care in Great Britain during the 1990s. Health \& Social Care in the Community, 9(6), 348-357.

Kahn, R. L., \& Antonucci, T. C. (1980). Convoys over the life course: Attachment, roles, and social support. Life-Span Development and Behavior, 3, 253-286.

Karlsson, M., Mayhew, L., Plumb, R., \& Rickayzen, B. (2006). Future costs for long-term care: Cost projections for long-term care for older people in the United Kingdom. Health Policy, 75(2), 187-213.

Keating, N., Oftinowski, P., Wenger, C., Fast, J., \& Derksen, L. (2003). Understanding the caring capacity of informal networks of frail seniors: A case for care networks. Ageing \& Society, 23(1), 115-127.

Konrad, K. A., Kunemund, H., Lommerud, K. E., \& Robledo, J. R. (2002). Geography of the family. The American Economic Review, 92(4), 981-998.

Lewis, J., \& Meredith, B. (1988). Daughters who care: Daughters caring for mothers at home. London, UK: Routledge.

Lilly, M. B., Laporte, A., \& Coyte, P. C. (2007). Labor market work and home care's unpaid caregivers: A systematic review of labor force participation rates, predictors of labor market withdrawal, and hours of work. Milbank Quarterly, 85(4), 641-690. 
Lyon, D., \& Glucksmann, M. (2008). Comparative configurations of care work across Europe. Sociology, 42(1), 101-118.

Nolan, M., Grant, G., \& Keady, J. (1996). Understanding family care: A multidimensional model of caring and coping. Buckingham, UK: Open University Press.

Norton, E. C., \& Van Houtven, C. H. (2006). Inter-vivos transfers and exchange. Southern Economic Journal, 73(1), 157-172.

Pezzin, L. E., Pollak, R. A., \& Schone, B. S. (2007). Efficiency in family bargaining: Living arrangements and caregiving decisions of adult children and disabled elderly parents. CESifo Economic Studies, 53(1), 69-96.

Phillipson, C. (2001). The family and community life of older people: Social networks and social support in three urban areas. London, UK: Routledge.

Pickard, L. (2012). Substitution between formal and informal care: A 'natural experiment' in social policy in Britain between 1985 and 2000. Ageing \& Society, 32(7), 1147-1175.

Pickard, L. (2014). A growing care gap? The supply of unpaid care for older people by their adult children in England to 2032. Ageing \& Society, Online, 1-28.

Pickard, L., Wittenberg, R., Comas-Herrera, A., King, D., \& Malley, J. (2007). Care by spouses, care by children: Projections of informal care for older people in England to 2031. Social Policy and Society, 6(3), 353-366.

Pinquart, M., \& Sorensen, S. (2003). Differences between caregivers and noncaregivers in psychological health and physical health: A meta-analysis. Psychology and Aging, 18(2), $250-267$.

Rainer, H., \& Siedler, T. (2009). O brother, where art thou? The effects of having a sibling on geographic mobility and labour market outcomes. Economica, 76(303), 528-556. 
Roe, B., Whattam, M., Young, H., \& Dimond, M. (2001). Elders' perceptions of formal and informal care: Aspects of getting and receiving help for their activities of daily living. Journal of Clinical Nursing, 10(3), 398-405.

Rummery, K., \& Fine, M. (2012). Care: A critical review of theory, policy and practice. Social Policy \& Administration, 46(3), 321-343.

Schulz, R., Mendelsohn, A. B., Haley, W. E., Mahoney, D., Allen, R. S., Zhang, S., et al. (2003). End-of-life care and the effects of bereavement on family caregivers of persons with dementia. New England Journal of Medicine, 349(20), 1936-1942.

Spiess, C. K., \& Schneider, A. U. (2003). Interactions between care-giving and paid work hours among European midlife women, 1994 to 1996. Ageing \& Society, 23(1), 41-68.

Stoller, E. P., \& Pugliesi, K. L. (1991). Size and effectiveness of informal helping networks: A panel study of older people in the community. Journal of Health and Social Behavior, 32(2), 180-191.

Ungerson, C. (1987). Policy is personal: Sex, gender, and informal care. London, UK: Tavistock Publications.

van Tilburg, T. (1998). Losing and gaining in old age: Changes in personal network size and social support in a four-year longitudinal study. The Journals of Gerontology Series B: Psychological Sciences and Social Sciences, 53B(6), S313-S323.

Wenger, G. C. (1991). A network typology: From theory to practice. Journal of Aging Studies, 5(2), 147-162.

Wenger, G. C., \& Keating, N. (2008). The evolution of networks of rural older adults. In N. Keating (Ed.), Rural ageing: A good place to grow old? (pp. 33-42). North Wales, UK: Policy Press.

Williams, F. (2004). Rethinking families. London, UK: Calouste Gulbenkian Foundation. 
Williams, F. (2010). Claiming and framing in the making of care policies: The recognition and redistribution of care. United Nations Research Institute for Social Development.

Willyard, J., Miller, K., Shoemaker, M., \& Addison, P. (2008). Making sense of sibling responsibility for family caregiving. Qualitative Health Research, 18(12), 1673-1686.

Figure 1: Network of care example 


\begin{tabular}{|c|c|c|c|}
\hline & No. of & Proportion of & \\
\hline & Households & Households in the & Fieldwork \\
\hline Network Type & in Sample & Population $^{\mathrm{a}}$ & Households $^{\mathrm{b}}$ \\
\hline No informal care & 3,328 & 52.65 & - \\
\hline (1) Care from spouse within household & 369 & 7.99 & $\begin{array}{l}\mathrm{C} ; \mathrm{G} ; \mathrm{H} ; \mathrm{I} ; \mathrm{P} ; \\
\mathrm{Q}\end{array}$ \\
\hline \multicolumn{4}{|l|}{ (2) Care from child(ren) outside the } \\
\hline \multicolumn{4}{|l|}{ household } \\
\hline (a) while living alone & 740 & 19.03 & $\mathrm{~B} ; \mathrm{L} ; \mathrm{S} ; \mathrm{T} ; \mathrm{W}$ \\
\hline (b) while living with others & 845 & 17.84 & - \\
\hline (3) Care from children living within & 103 & 1.75 & $\mathrm{E} ; \mathrm{O} ; \mathrm{X}$ \\
\hline \multicolumn{4}{|l|}{ household } \\
\hline (4) Other living arrangements & 44 & 0.74 & $\mathrm{~F} ; \mathrm{J} ; \mathrm{Y}$ \\
\hline
\end{tabular}

Total No. of Households 5,429

a Weighted using the supplied household survey weights.

b Letters are functioning as pseudonyms, each indicating a separate household. 


\begin{tabular}{|c|c|c|c|c|c|}
\hline & Age of & & & & No. \\
\hline & Oldest & Mean & Social & Rural & People in \\
\hline & Householder & Income per & Rented/Public & Household & Household \\
\hline Network Type & (mean) & Person $(£)$ & Housing $(\%)$ & $(\%)$ & (Mean) \\
\hline No informal care & 65.2 & 15,366 & 12.92 & 27.13 & 2.07 \\
\hline (1) Living with a spouse & & & & & \\
\hline providing care & 71.5 & 10,707 & 25.8 & 21.94 & 2.38 \\
\hline (2) Care from child(ren) & & & & & \\
\hline outside the household & & & & & \\
\hline (a) while living alone & 77.2 & 11,928 & 33.74 & 24.21 & 1 \\
\hline (b) while living with & & & & & \\
\hline others & 65.5 & 13,128 & 13.29 & 25.48 & 2.34 \\
\hline (3) Living with children & & & & & \\
\hline providing care & 80.5 & 10,815 & 16.83 & 17.9 & 3.05 \\
\hline (4) Other living arrangements & 73.2 & 8,840 & 18.27 & 4.65 & 1.94 \\
\hline
\end{tabular}

Table 3: Number of fieldwork participants by age group, sex, and caring role

\begin{tabular}{|c|c|c|c|c|c|}
\hline \multirow{2}{*}{$\begin{array}{l}\text { Age of } \\
\text { Participants }\end{array}$} & \multicolumn{2}{|l|}{ Carers } & \multicolumn{2}{|c|}{ Care Recipients } & \multirow[b]{2}{*}{ Total } \\
\hline & Female & Male & Female & Male & \\
\hline$<55$ years & 1 & - & - & - & 1 \\
\hline 55 to 64 years & 3 & - & - & - & 3 \\
\hline
\end{tabular}




\begin{tabular}{llllll}
65 to 74 years & 2 & - & 2 & 2 & 6 \\
Over 75 years & 1 & 1 & 9 & 6 & 17 \\
\hline Total & $\mathbf{7}$ & $\mathbf{1}$ & $\mathbf{1 1}$ & $\mathbf{8}$ & $\mathbf{2 7}$
\end{tabular}

Table 4: Living with a spouse: Percentages of household care networks by number of links

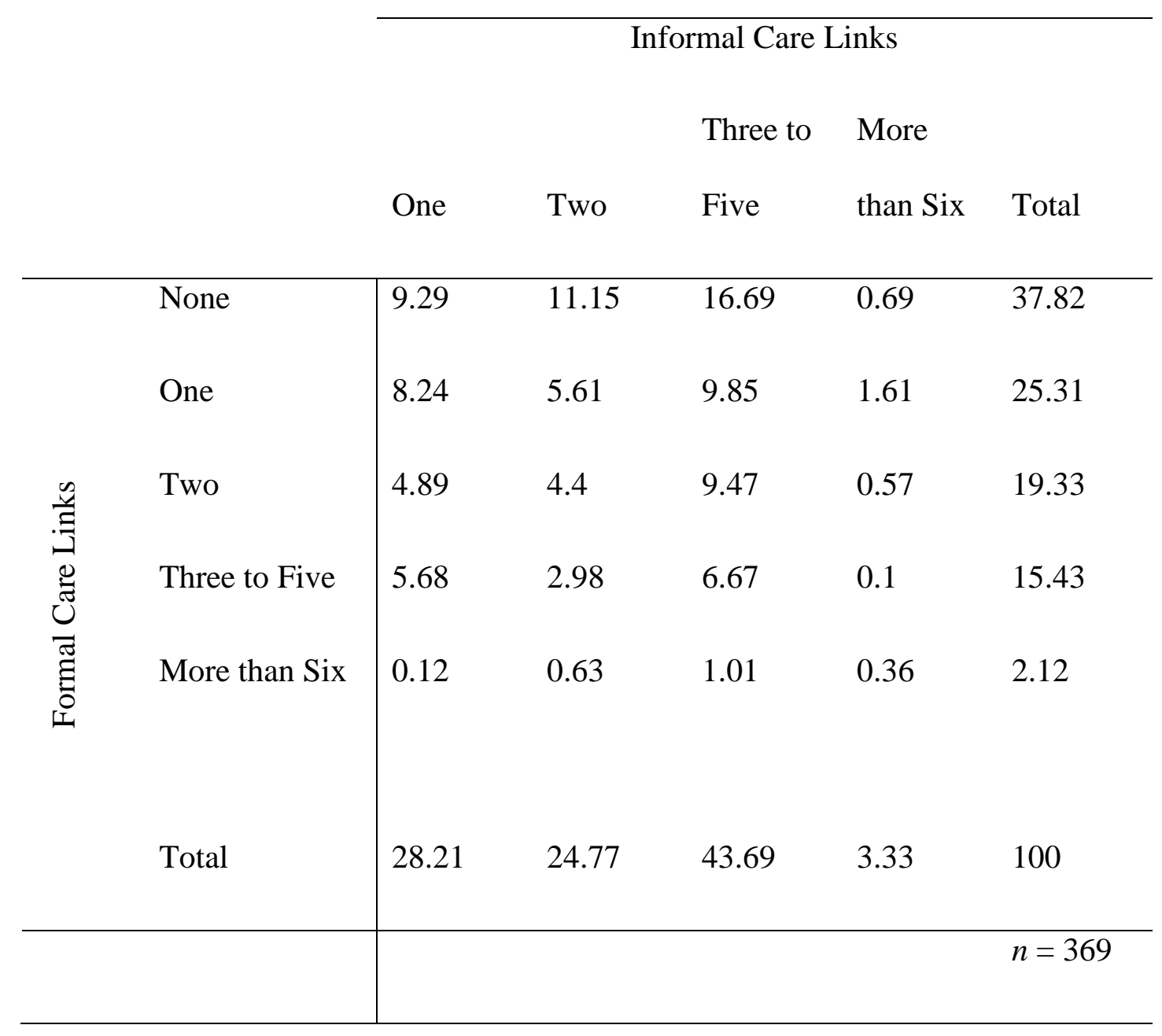

Table 5: Support from outside the household: Percentages of household care networks by number of links (living alone) 


\begin{tabular}{|c|c|c|c|c|c|c|}
\hline & & \multicolumn{5}{|c|}{ Informal Care Links } \\
\hline & & & & Three to & More & \\
\hline & & One & Two & Five & than Six & Total \\
\hline \multirow{7}{*}{ 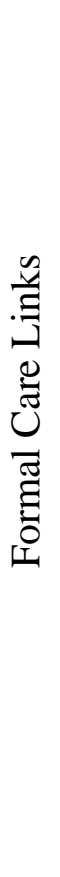 } & None & 52.07 & 8.49 & 1.52 & - & 62.07 \\
\hline & One & 19.71 & 3 & 0.65 & - & 23.36 \\
\hline & Two & 6.58 & 0.16 & 0.33 & - & 7.07 \\
\hline & Three to Five & 5.96 & 1.12 & 0.15 & - & 7.23 \\
\hline & More than Six & 0.26 & - & - & - & 0.26 \\
\hline & \multirow[t]{2}{*}{ Total } & 84.58 & 12.77 & 2.65 & - & 100 \\
\hline & & & & & & $n=740$ \\
\hline
\end{tabular}


Table 6: Support from outside the household: Percentages of household care networks by number of links (living with others)

\begin{tabular}{|c|c|c|c|c|c|c|}
\hline & & \multicolumn{5}{|c|}{ Informal Care Links } \\
\hline & & \multirow[b]{2}{*}{ One } & \multirow[b]{2}{*}{ Two } & \multirow{2}{*}{$\begin{array}{l}\text { Three to } \\
\text { Five }\end{array}$} & \multirow{2}{*}{$\begin{array}{l}\text { More } \\
\text { than Six }\end{array}$} & \multirow[b]{2}{*}{ Total } \\
\hline & & & & & & \\
\hline \multirow{7}{*}{ 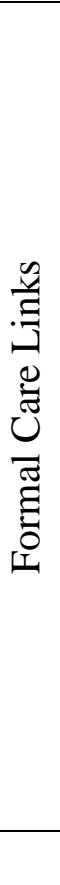 } & None & 34.83 & 22.07 & 11.17 & 0.3 & 68.37 \\
\hline & One & 9.15 & 7.52 & 4.15 & 一 & 20.81 \\
\hline & Two & 2.99 & 4.09 & 1.15 & 0.02 & 8.26 \\
\hline & Three to Five & 0.34 & 1.28 & 0.65 & - & 2.27 \\
\hline & More than Six & 0.29 & - & - & - & 0.29 \\
\hline & \multirow[t]{2}{*}{ Total } & 47.6 & 34.96 & 17.12 & 0.32 & 100 \\
\hline & & & & & & $n=845$ \\
\hline
\end{tabular}

Table 7: Living with children: Percentages of household care networks by number of links

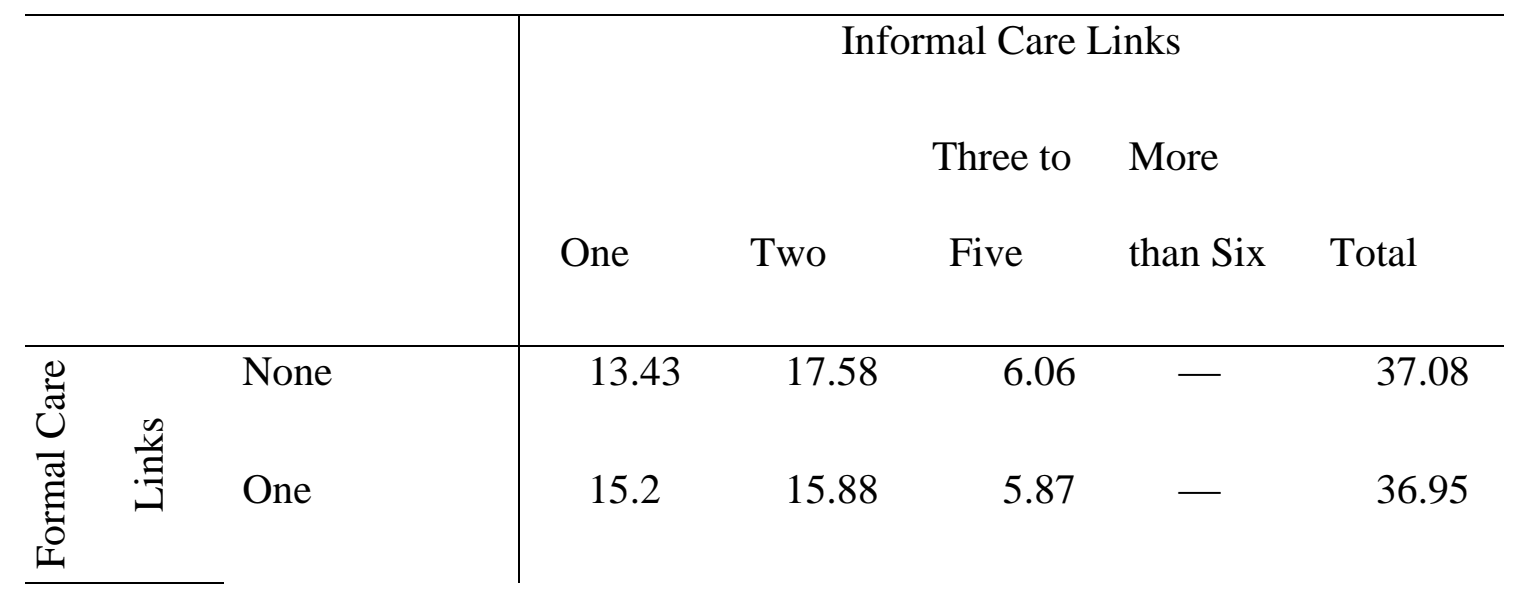




\begin{tabular}{|c|c|c|c|c|c|}
\hline & \multicolumn{5}{|c|}{ Informal Care Links } \\
\hline & & & Three to & More & \\
\hline & One & Two & Five & than Six & Total \\
\hline Two & 4.76 & 0.5 & 6.17 & 0.18 & 11.62 \\
\hline Three to Five & 4.89 & 6.08 & 2.76 & - & 13.73 \\
\hline More than Six & - & - & 0.63 & - & 0.63 \\
\hline Total & 38.29 & 40.04 & 21.49 & 0.18 & 100 \\
\hline & & & & & $n=103$ \\
\hline
\end{tabular}

Table 8: Other care networks: Percentages of household care networks by number of links

\begin{tabular}{|c|c|c|c|c|c|c|}
\hline & & \multicolumn{5}{|c|}{ Informal Care Links } \\
\hline & & \multirow[b]{2}{*}{ One } & \multirow[b]{2}{*}{ Two } & \multirow{2}{*}{$\begin{array}{l}\text { Three to } \\
\text { Five }\end{array}$} & \multirow{2}{*}{$\begin{array}{l}\text { More } \\
\text { than Six }\end{array}$} & \multirow[b]{2}{*}{ Total } \\
\hline & & & & & & \\
\hline \multirow{5}{*}{ 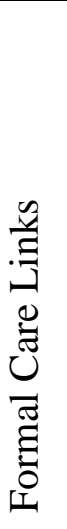 } & None & 31.6 & 7.72 & 2.99 & - & 42.31 \\
\hline & One & 12.79 & 16.59 & - & - & 29.37 \\
\hline & Two & 7.74 & 4.06 & 6.71 & - & 18.5 \\
\hline & Three to Five & 8.19 & 0.49 & 1.13 & - & 9.81 \\
\hline & More than Six & - & - & - & - & - \\
\hline
\end{tabular}




\begin{tabular}{|c|c|c|c|c|c|}
\hline & \multicolumn{5}{|c|}{ Informal Care Links } \\
\hline & & & Three to & More & \\
\hline & One & Two & Five & than Six & Total \\
\hline \multirow[t]{2}{*}{ Total } & 60.32 & 28.86 & 10.82 & - & 100 \\
\hline & & & & & $n=44$ \\
\hline
\end{tabular}

